\title{
International Society for the Advancement of Spine Surgery Policy 2019-Surgical Treatment of Lumbar Disc Herniation with Radiculopathy
}

\author{
MORGAN LORIO, MD, FACS, ${ }^{1}$ CHOLL KIM, MD, PHD, ${ }^{2}$ ALI ARAGHI, DO, ${ }^{3}$ JASON INZANA, PHD, ${ }^{4}$ \\ JAMES J. YUE, MD \\ ${ }^{I}$ Advanced Orthopedics, Altamonte Springs, Florida, ${ }^{2}$ Spine Institute of San Diego, San Diego, California,${ }^{3}$ The CORE Institute, Sun City West, Arizona, ${ }^{4}$ Telos \\ Partners, LLC, Denver, Colorado, ${ }^{5}$ CT Orthopaedics; Frank H. Netter School of Medicine, Hamden, Connecticut
}

\begin{abstract}
Lumbar disc herniation (LDH) is a frequent cause of low back pain and radiculopathy, disability, and diminution in quality of life. While nonsurgical care remains the mainstay of initial treatment, symptoms that persist for prolonged periods of time are well treated with discectomy surgery. A large body of evidence shows that, in patients with unremitting symptoms despite a reasonable period of nonsurgical treatment, discectomy surgery is safe and efficacious. In patients with symptoms lasting greater than 6 weeks, various forms of discectomy (open, microtubular, and endoscopic) are superior to continued nonsurgical treatment. The small but significant proportion of patients with recurrent disc herniation experience less improvement overall than patients who do not experience reherniation after primary discectomy. Lumbar discectomy patients with large annular defects $(\geq 6 \mathrm{~mm}$ wide) are at a higher risk for recurrent herniation and revision surgery. Annular closure via a bone-anchored device has been shown to decrease the rate of recurrent disc herniation and associated reoperation in these high-risk patients. After a detailed review of the literature, current clinical evidence supports discectomy (open, microtubular, or endoscopic discectomy) as a medically necessary procedure for the treatment of LDH with radiculopathy in indicated patients. Furthermore, there is new scientific evidence that supports the use of bone-anchored annular closure in patients with large annular defects, who are at greater risk for recurrent disc herniation.
\end{abstract}

Testing \& Regulatory Affairs

Keywords: lumbar disc herniation, radiculopathy, discectomy, annular closure

\section{INTRODUCTION}

Lumbar disc herniation ( $\mathrm{LDH})$ is a localized displacement of intervertebral disc material beyond the normal perimeter of the disc space. ${ }^{1,2}$ Depending on the volume, location, and type of herniation, adjacent neural structures may become compressed, resulting in radiculopathy associated with pain, numbness, or weakness. ${ }^{3,4}$ Impingement of the lumbosacral nerves by a herniated disc is the leading cause of sciatica, which is characterized by low back pain and radiating leg pain. ${ }^{5}$

Patient history and physical examination are the most important steps in the diagnosis of LDH with radiculopathy. ${ }^{1}$ The physical examination may include manual muscle testing, sensory testing, supine straight leg raise, Lasegue's sign, and crossed Lasegue's sign. ${ }^{1}$ Other functional tests (eg, Bell test, hyperextension test, reflex tests, nerve stretch test, lumbar range of motion test) have varying degrees of sensitivity and specificity, but can be incorporated depending on a physician's experience and preference. ${ }^{1,6}$ If the patient history and physical examination results are consistent with symptomatic $\mathrm{LDH}$, noninvasive visualization of the neural structures is used to confirm disc herniation. Magnetic resonance imaging (MRI) is considered the most appropriate modality to confirm LDH, but computed tomography (CT) with or without myelography should be considered if MRI is contraindicated or inconclusive. ${ }^{7,8}$

Many patients with symptomatic LDH, particularly those with mild or moderate symptoms, will improve with nonsurgical management, which may include manual spinal manipulation, physical therapy, nonsteroidal anti-inflammatory drugs, analgesics, and/or corticosteroid injections. ${ }^{1,9,10}$ Results from randomized controlled trials (RCTs) have shown that $35 \%$ to $54 \%$ of patients assigned to 
continued nonsurgical care undergo discectomy within 6 months due to persistent or aggravating symptoms. ${ }^{1-14}$ A survey of 814 neurosurgeons found that $46 \%$ of respondents recommended a minimum of 4 to 8 weeks of nonsurgical management before surgery is indicated, $34 \%$ recommended 8 weeks or more, and $20 \%$ recommended less than 4 weeks. $^{15}$ Based on a health technology assessment, which included a systematic literature review, public feedback, and voting from a clinical committee, the Washington State Health Care Authority requires at least 6 weeks of nonsurgical care unless progressive motor weakness is present. ${ }^{16,17}$ Thus, the decision to continue nonsurgical care or undergo surgery considers the patient history, physical examination, radiological findings, and severity of symptoms.

When surgery is indicated, discectomy is the primary surgical intervention for $\mathrm{LDH}$ with radiculopathy. ${ }^{18}$ The principal goals of discectomy are to surgically remove the displaced disc material, decompress the affected neural structures to relieve symptoms, and minimize the chance of recurrence by removing loose or degenerated material from the intervertebral space and surrounding area. Discectomy can be performed through an open, mini-open (eg, microtubular), or endoscopic approach. Each of these methods enables direct, light-based visualization, in contrast to percutaneous techniques that solely use intra-operative radiological imaging for indirect visualization.

Upon completion of the discectomy, prior to closure, there are currently no widely accepted practices for repair of the annulus fibrosus. Studies have shown that large ( $\geq 6 \mathrm{~mm}$ wide), unrepaired annular defects increase the risk of symptom recurrence and additional surgery. ${ }^{19,20}$ These data have led to the development of several annular closure or repair devices to help reduce the risk of recurrence and reoperation in this high-risk patient population. Most of those techniques and closure systems lacked clinical evidence and are no longer commercially available. A bone-anchored implant is Food and Drug Administration (FDA) approved and has clinical evidence demonstrating effectiveness for large annular defects.

The aim of this International Society for the Advancement of Spine Surgery (ISASS) Policy Statement is to discuss the evidence from RCTs, prospective cohort studies, and recent meta-analyses to inform treatment and coverage recommendations for primary discectomy and annular repair in indicated patients with LDH and radiculopathy.

\section{SUMMARY OF THE CLINICAL EVIDENCE}

\section{Discectomy Versus Nonsurgical Care for LDH With Radiculopathy}

Several RCTs and prospective cohort studies have shown that discectomy provides faster and/or greater pain relief, recovery from disability, and patient satisfaction compared to continued nonsurgical care (Table 1). ${ }^{11-14,21,22}$ Clinical evidence also indicates that discectomy-related surgical complications are rare. The most common complications include dural tears $(1 \%-4 \%$ of cases $),{ }^{11,13,14,21,23}$ blood transfusions $(2 \%-3 \%$ of cases $),{ }^{14,21,23}$ and neural injuries $(0.4 \%$ of cases $) .{ }^{21}$ None of the RCTs or prospective cohort studies reported cases of perioperative mortality, ${ }^{11-14,17,21-25}$ indicating that the risk of discectomy-related death is negligible. A recent (2019) analysis of 34639 LDH operations performed over 15 years found that complications occurred in only $2.7 \%$ (95\% confidence interval: $2.6 \%-2.9 \%$ ) of cases, with no perioperative deaths. ${ }^{18}$

Early evidence on the efficacy of discectomy for symptomatic LDH came from a large, multicenter prospective cohort study called the Maine Lumbar Spine Study (MLSS). ${ }^{21}$ The MLSS involved 275 patients treated surgically and 232 treated with nonsurgical care. At the 1-year follow-up, patients treated with discectomy reported greater improvement in back and leg pain $(P<.001)$, functional status $(P<.001)$, and overall satisfaction $(P=.005)$ compared to nonsurgical care. ${ }^{21}$ Additionally, a larger percentage of patients in the discectomy group reported complete relief from their predominant symptoms $(31 \%$ versus $11 \%$; $P<.001)$. Long-term follow-up analyses in the MLSS reported that these greater improvements among discectomy-treated patients persisted over 5 years for leg pain, back pain, function, and satisfaction $(P \leq .001)$ and over 8 to 10 years for leg pain and function $(P<.05) .^{26,27}$

The Spine Patient Outcomes Research Trial (SPORT) is a large, National Institutes of Healthfunded, multicenter RCT and an observational cohort study comparing discectomy versus nonsurgical care in patients with lumbar radiculopathy secondary to LDH. The RCT included 501 patients 
with confirmed symptomatic LDH treated with discectomy $(n=245)$ or nonsurgical care $(\mathrm{n}=256) .{ }^{14}$ Patients eligible for surgery had radicular pain, a positive straight leg test, or neurologic deficit, failed at least 6 weeks of nonsurgical care, and had radiologically confirmed $\mathrm{LDH}$. In the RCT arm of the study, $45 \%$ of patients randomized to nonsurgical care crossed over to surgery, and $40 \%$ of patients randomized to surgery chose to continue with nonsurgical care. Furthermore, patients that crossed over to surgery had significantly worse baseline scores for Short Form 36 (SF-36) bodily pain $(P=.03)$ and function $(P<.001)$, Oswestry Disability Index (ODI; $P<.001)$, sciatica frequency $(P=.009)$, and sciatica bothersomeness $(P=.001)$. These confounding events likely explain why the intent-to-treat (ITT) analysis did not detect significant differences in pain, function, or disability between treatment groups. ITT analysis is intended to reduce the risk of bias by evaluating results according to the randomized treatment allocation, irrespective of the treatment that patients actually received. ${ }^{28}$ In RCTs with high crossover or nonadherence rates, ITT analyses are difficult to interpret, and an as-treated analysis is recommended to determine the treatment effect. ${ }^{29}$ In the SPORT RCT, an as-treated analysis evaluated outcomes based on the adjusted covariates of time and treatments actually received. ${ }^{14}$ Those results showed significantly better improvements in the SF36 pain and function scores, ODI, sciatica scores, as well as higher patient satisfaction, at all timepoints in the discectomy group compared to nonsurgical care. $^{14}$

In addition to randomized patients, SPORT also included observational cohorts comprised of patients that declined to be in the $\mathrm{RCT}^{23}$ In the observational cohorts, 528 patients were treated with discectomy, and 191 patients received nonsurgical care over the first 2 years. Compared to the nonsurgical group, patients in the discectomy group had significantly greater improvements in primary outcomes (ie, bodily pain, physical function, and ODI) and secondary outcomes (ie, sciatica bothersomeness, satisfaction, and self-rated improvement) over 2 years of follow up $(P<.001$ for all metrics). ${ }^{23}$ An as-treated subgroup analysis of combined observational and randomized cohorts demonstrated that all 37 subgroups experienced significantly greater improvements with discectomy compared to nonsurgical care $(P<.05) .{ }^{30}$ Some of the subgroups with the greatest treatment effect from discectomy included older patients (age $>41$ years), those with deteriorating symptoms at baseline, and those without joint problems. ${ }^{30}$ Longer term follow-up studies of the combined SPORT cohorts confirmed that the benefits of discectomy persisted through 8 years. ${ }^{31-33}$ As-treated analyses at 8 years follow up adjusted for potential covariates, such as demographics, smoking status, and LDH location, which demonstrated significant benefits in favor of discectomy for all primary and secondary outcomes of pain, function, sciatica bothersomeness, patient satisfaction, and self-rated improvement $(P<.001$ for all metrics $){ }^{33}$ Together, the SPORT study as a whole represents robust and high-quality clinical evidence in support of discectomy compared with nonsurgical care in both shortand long-term benefits for treatment of LDH with radiculopathy among indicated patients.

Three more RCTs and 1 prospective cohort study demonstrated positive outcomes with discectomy compared to nonsurgical care at early timepoints. ${ }^{1-13,22}$ Peul et al ${ }^{11}$ conducted a multicenter RCT comparing 141 patients treated with discectomy versus 142 patients treated with continued nonsurgical care. All patients had radiculopathy and radiologically confirmed LDH. Thirty-nine percent of patients assigned to nonsurgical care crossed over to discectomy within 1 year, and $11 \%$ assigned to surgery continued with nonsurgical care. Based on ITT analysis, discectomy resulted in greater symptom relief at early timepoints of 2 to 12 weeks. By 1 year, the differences were not statistically significant; however, this finding, based on ITT analysis, is confounded by the high crossover rate from nonsurgical care to discectomy. The authors did not report analysis of the as-treated populations.

Butterman conducted a single-site RCT comparing 50 patients treated with discectomy versus 50 patients treated with epidural steroid injections. ${ }^{13}$ All patients had clinical symptoms of $\mathrm{LDH}$, radiologically confirmed disc herniation that encompassed more than $25 \%$ of the spinal canal crosssectional area, and failed at least 6 weeks of nonsurgical care. Twenty-seven (54\%) patients failed epidural steroid injection treatment and crossed over to discectomy. The results demonstrated that discectomy significantly improved leg pain, bodily pain, ODI, and neurological deficit scores 1 to 3 months after surgery $(P<.05)$, suggesting an early clinical benefit of discectomy. After 3 months, 


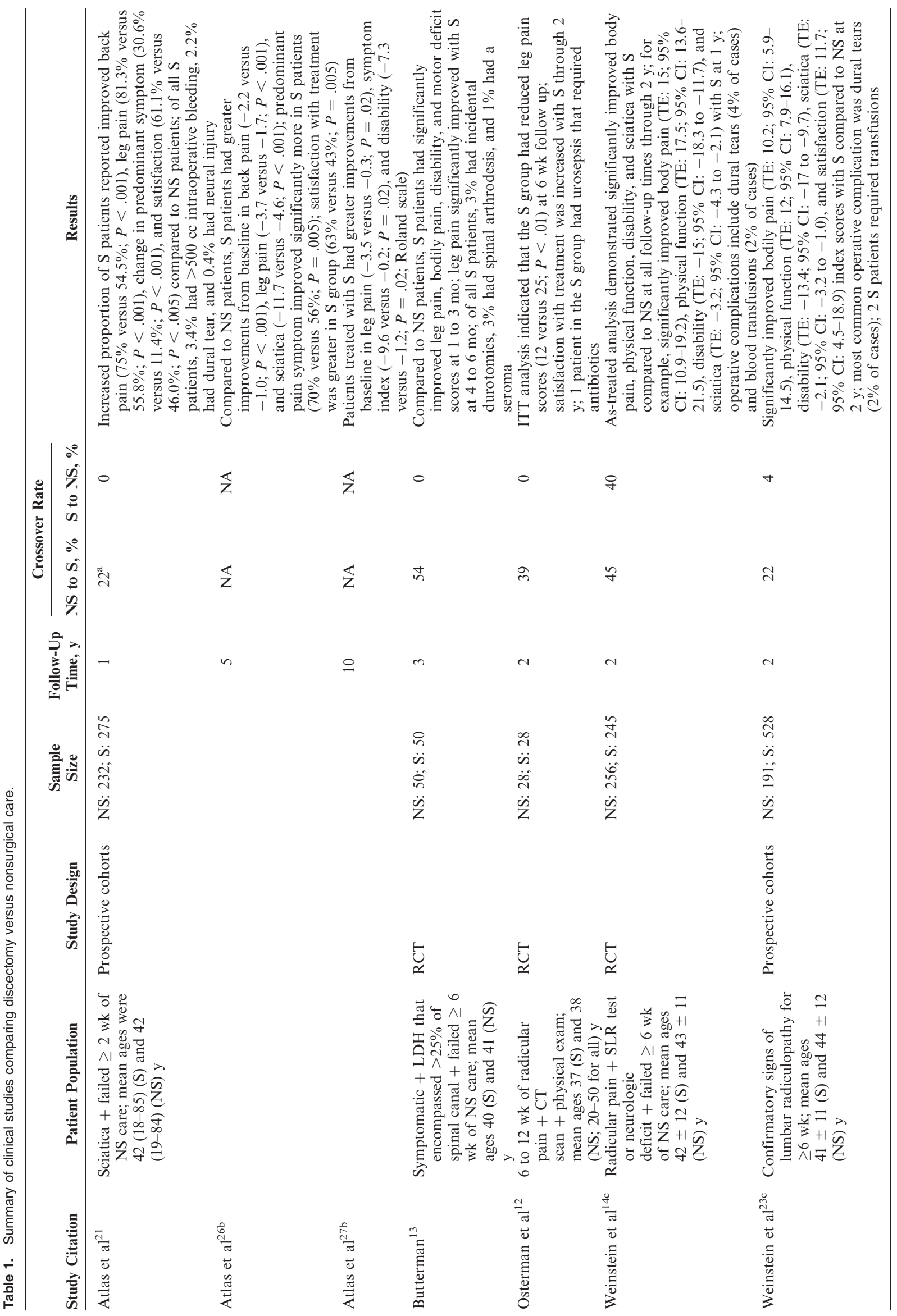




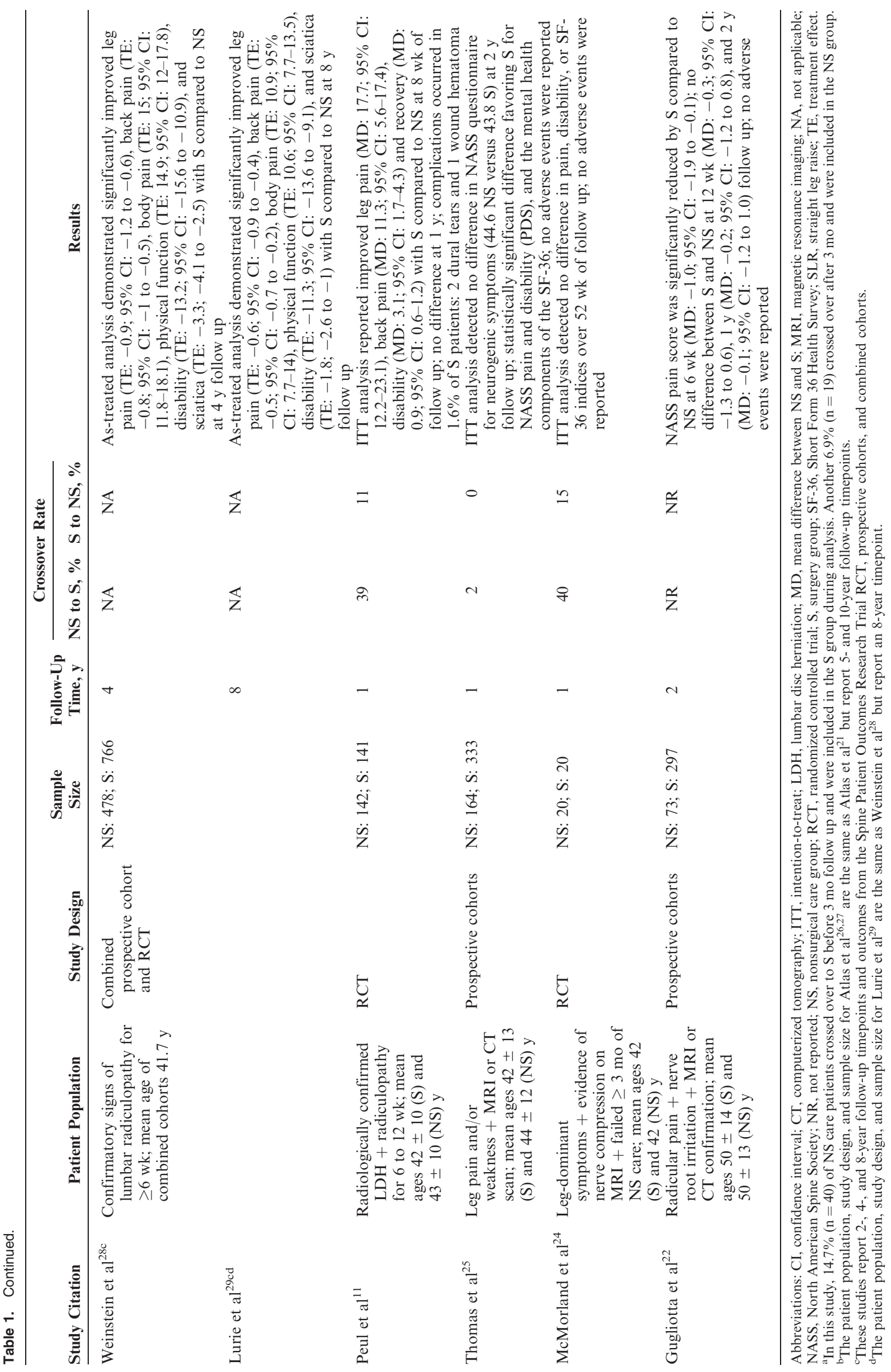


outcomes measures were not statistically different between treatment groups; the only exception was that leg pain was improved with discectomy at 4 to 6 months $(P<.05)$.

Österman et $\mathrm{al}^{12}$ conducted a small RCT analyzing 56 patients: 28 treated with discectomy and 28 with nonsurgical care. Similar to SPORT and Peul et al, $39 \%$ of patients randomized to nonsurgical care underwent surgery by 1 year. All patients allocated to the surgery group underwent discectomy. Results from the ITT analysis showed that patients treated with discectomy had significantly greater patient satisfaction through 2 years of follow up and an early advantage in the reduction of leg pain at 6 weeks follow up. Additional trends in favor of discectomy were noted; however, interpretation is limited by the small sample size and large number of crossover patients.

Recently, in a prospective cohort study, Gugliotta et $\mathrm{al}^{22}$ reported that patients treated with discectomy had significantly reduced North American Spine Society (NASS) questionnaire back pain at 6 weeks compared to nonsurgical treatment, indicating a faster improvement in pain with discectomy. No differences were observed at later timepoints; however, $42 \%$ of patients in the surgery group and $55 \%$ in the nonsurgical care group were lost to follow up, which limits the data quality at later timepoints.

In contrast, 1 RCT of 40 patients and 1 prospective cohort study of 497 patients concluded that there were no significant differences in patient outcomes between discectomy and nonsurgical care for symptomatic LDH at 1 year. ${ }^{24,25}$ Interpretation of the RCT was limited by a small sample size, large rate of crossover $(40 \%)$ in the ITT analysis, and a lack of as-treated analysis. ${ }^{24}$ In the cohort study, patients treated with discectomy and nonsurgical care experienced a similar, nonsignificant $(P=.58)$ improvement in the primary outcome (ie, NASS neurogenic symptoms score) after adjusting for covariates. $^{25}$ However, the discectomy group achieved significantly greater improvements in the pain and disability scores as well as the mental component summary of the SF-36 $(P<.05)$, even after adjustment for covariates. ${ }^{25}$

A 2019 systematic review and meta-analysis examined 11 studies (3232 patients) comparing discectomy versus nonsurgical care. ${ }^{34}$ Discectomy was found to be more effective than nonsurgical care in significantly reducing leg pain $(P<.001)$ and back pain $(P=.02)$. The authors also reported a trend towards greater reductions in disability after discectomy, but the comparison was not statistically significant $(P=.09)$. Comparison of any surgical intervention with nonsurgical care can be challenging and such studies require careful interpretation (eg, ITT versus as-treated analyses with adjustment for covariates). While studies of discectomy versus nonsurgical care can be confounded by high crossover rates and expectation bias, ${ }^{35}$ the astreated analyses consistently observed a significant benefit of surgery among indicated patients.

Comparisons of discectomy with an active control may help limit expectation bias and crossover rates. Accordingly, a Cochrane Systematic Review of RCTs on surgical interventions for LDH also compared discectomy with chemonucleolysis. ${ }^{36}$ Meta-analyses in the Cochrane Review demonstrated strong evidence for superiority of chemonucleolysis over placebo as well as strong evidence for the superiority of discectomy over chemonucleolysis, which also suggests that discectomy is more effective than placebo. ${ }^{36}$

\section{Endoscopic Versus Open Discectomy}

Endoscopic discectomy is a minimally invasive technique designed to reduce tissue trauma compared to open discectomy. ${ }^{37,38}$ As with an open procedure, an endoscopic approach allows for full access to the herniated disc under direct visualization using an endoscope. Advantages of endoscopic compared to open discectomy include reduced incision size and soft tissue damage, which may be associated with faster recovery. ${ }^{39}$ The transforaminal endoscopic approach obviates the need for removal of laminar bone and ligamentum flavum, resulting in less alteration of the anatomy. Disadvantages include an unfamiliar approach to most surgeons and a learning curve, making this approach technically challenging for many surgeons. ${ }^{40}$

Clinical studies and meta-analyses have shown that patients treated with endoscopic discectomy experience similar improvements in function and symptom relief when compared to traditional open discectomy or microdiscectomy. ${ }^{38,41-45}$ Ruetten et $\mathrm{al}^{38}$ performed a seminal 200-patient RCT, with randomization to either conventional microdiscectomy $(\mathrm{n}=100)$ or full-endoscopic discectomy (transforaminal, $\mathrm{n}=41$; interlaminar, $\mathrm{n}=59$ ). There were no serious complications in either group, but the microdiscectomy group had a significantly 
higher rate of nonserious complications, such as postoperative bleeding or delayed wound healing $(P<.05)$. Recurrent herniation rates were also similar between the groups, but the rate of recurrence was significantly higher among patients who had a large versus small annular defect, regardless of treatment type $(P<.01)$. Clinical outcomes, such as leg pain and disability scores, were significantly improved in both groups through 2 years follow up ( $89 \%$ follow-up rate), with no significant differences between groups. However, the endoscopic group reported significantly less postoperative pain, less pain medication use, and fewer postoperative work disability days (25 days versus 49 days) than the microdiscectomy group $(P<.01)$.

Gibson et $\mathrm{al}^{42}$ performed a prospective RCT comparing 70 patients treated with transforaminal endoscopic discectomy (TED) versus 70 patients treated with microdiscectomy and observed similar outcomes for improvements in pain and disability between the 2 groups. However, patients in the TED group had a shorter mean hospital stay ( 0.7 versus 1.4 nights; $P<.001$ ), suggesting a faster recovery time. Zhang et $\mathrm{al}^{45}$ reported results from a systematic review of 9 studies (1527 patients) comparing microdiscectomy with TED. Results from the meta-analysis suggested that there were no significant differences in visual analog scale (VAS) leg pain, recovery of function following surgery, operative time, or incidence of complications. Similar to the study by Gibson et al, endoscopic discectomy significantly reduced the length of hospital stay $(P<.001)$.

\section{Prevention of Recurrent LDH}

Although primary discectomy is an effective treatment for $\mathrm{LDH}$ with radiculopathy, a small proportion of patients $(5 \%-15 \%)$ experience symptomatic recurrent $\mathrm{LDH}(\mathrm{rLDH}),{ }^{19,46,47}$ and $4 \%$ to $6 \%$ undergo revision surgery within 2 years. ${ }^{48-50}$ Techniques for management of recurrent herniation are dependent upon the specific patient indications and the surgeon's experience, on a case-by-case basis. Regardless of the reoperation strategy, clinical evidence has shown that patients who undergo revision surgery for symptomatic rLDH have worse clinical outcomes (eg, pain and disability) compared to patients who do not reherniate following primary discectomy. ${ }^{51-57}$ Abdu et $\mathrm{al}^{52}$ observed that $9.1 \%$ of the 810 SPORT patients treated with discectomy experienced rLDH and revision surgery during the 8-year follow-up period. Compared to patients that did not reherniate, those with $\mathrm{rLDH}$ and revision surgery had significantly worse SF-36 bodily pain, ODI, and sciatica bothersomeness scores at 4 years follow up $(P \leq .001$ for all metrics). Similarly, a study of patient-reported outcomes from a large registry (Swespine) demonstrated that patients who underwent revision surgery for $\mathrm{rLDH}$ experienced significantly less improvement in VAS leg pain, VAS back pain, ODI, and EQ-5D health status compared to the primary LDH group $\left(P \leq .001\right.$ for all metrics) ${ }^{53}$

Patient factors that may increase the risk of rLDH include younger age, male gender, work that requires lifting, worse baseline pain and disability, lack of motor or sensory deficit, smoking, and diabetes. ${ }^{46,52,58}$ An important risk factor for symptomatic $\mathrm{rLDH}$ that may be addressable by the surgeon is a large annular defect ( $\geq 6 \mathrm{~mm}$ wide). A recent (2018) meta-analysis reported that a large annular defect increases the odds of a patient experiencing symptom recurrence or revision surgery by a factor of 2.5 or 2.3 , respectively. ${ }^{20}$ There is an unmet medical need to address this elevated risk in patients with large annular defects and avoid the worse outcomes associated with revision. ${ }^{59}$ Several devices have been designed to help repair large annular defects, including soft tissue suture kits and bone-anchored annular closure devices (ACDs). While discectomy is intended to alleviate patient symptoms by decompressing the impinged neural structures, annular repair is intended to reduce the risk of recurrence and revision, thereby sustaining the clinical benefits of the primary discectomy.

Currently, clinical evidence exists for 2 annular repair methods: (1) closure of the annular defect using a soft tissue suture kit and (2) implantation of a bone-anchored ACD. Bailey et $\mathrm{al}^{60}$ described a 750-patient RCT to study annular repair using a soft tissue suture system that was commercially available at the time of the study. Patients were randomized 2:1 to annular repair or no annular repair (control) after discectomy. Included subjects were candidates for 1- or 2-level lumbar discectomy, had persistent and predominant leg pain (VAS leg $>4 / 10$ ), and were not responsive to 6 weeks of nonsurgical care. No inclusion or exclusion criteria specified the size of the annular defect. The authors reported that annulotomy was performed in $77 \%$ of patients, producing annular defects with a mean size of $4.75 \pm 2.0 \mathrm{~mm}$. Assuming a normal distribution, 
$73 \%$ of annulotomy patients had a defect size less than $6 \mathrm{~mm}$, which is commonly described as the threshold for "large" defects. ${ }^{20,59}$ There were no significant differences in rates of adverse events or serious adverse events (SAEs) between the 2 groups. Clinical outcomes of leg pain, back pain, disability, and physical function were also similar between the groups over 2 years of follow up. While there was a trend of reduced rLDH-related reoperations over 2 years in the annular repair group, the results were not statistically significant $(9.7 \%$ versus $11.2 \%$; $P=.56$ ). The marginal reductions in reoperation rate may have been related to the fact that most patients did not have a large annular defect. In the subgroup with predominant leg pain, the rate of rLDH-related reoperations was significantly reduced in the annular repair group at 3 months $(1.0 \%$ versus $5.9 \% ; P=.019)$ and 6 months $(2.0 \%$ versus $6.9 \% ; P=.046)$ follow up, but not at 2 years (6.7\% versus $12.1 \% ; P=.13)$.

Several clinical studies, including 2 RCTs and a prospective comparative cohort study, ${ }^{61-63}$ have shown that bone-anchored ACD implantation reduces the risk of symptomatic rLDH and reoperation compared with discectomy alone (Table 2). Four additional prospective cohort or registry studies have also observed positive outcomes and low revision rates with this treatment technique. ${ }^{64-68}$ One multicenter RCT analyzed 550 patients with large $(\geq 6 \mathrm{~mm}$ wide) annular defects who were randomized 1:1 to treatment with discectomy alone $(\mathrm{n}=278)$ or discectomy plus a bone-anchored ACD $(\mathrm{n}=272) .{ }^{62,69}$ The ACD group experienced a significantly lower rate of symptomatic rLDH $(12 \%$ versus $25 \% ; P<.001)$ and related revision surgeries $(5 \%$ versus $13 \% ; P=.001)$ compared to discectomy alone over 2 years of follow up. ${ }^{62}$ At 3 and 4 years follow up, the ACD group also experienced significantly greater improvement in pain, disability, and health-related quality of life scores compared to discectomy alone $(P<.05) .^{70,71}$ Based on Kaplan-Meier survival analysis, the incidence rates continued to be lower in the ACD group over a 5 year follow up for symptomatic index-level $\mathrm{rLDH}(21.8 \%$ versus $32.8 \% ; P<.001)$ and index-level reoperation $(16.2 \%$ versus $22.7 \%$; $P=.03)^{72}$

According to the FDA's Summary of Safety and Effectiveness Data (SSED) related to this device and RCT, there were $34(12.7 \%)$ device deficiencies comprised of 5 anchor migrations and 29 events related to the occlusion component. ${ }^{72}$ Approximately half of the deficiencies were asymptomatic, and 12 $(4.5 \%)$ of those deficiencies were related to a SAE. Despite these device-related complications, the ACD group experienced significantly fewer deviceor procedure-related SAEs over a 5-year time period $(P=.037)$ due to the reduction in symptomatic rLDH rates. $^{72}$ The SSED also described the observation of radiographic endplate lesions (EPLs) on CT images at a significantly higher rate in the ACD group $(89 \%$ versus $41 \% ; P<.001)$. However, the size of $90 \%$ of the EPLs in both groups stabilized over the 3- to 5-year observation period. Further, in the ACD group, no negative clinical outcomes were associated with the EPLs, based on patient-reported outcomes, reoperations, or SAEs. Current evidence suggests that the EPLs do not impact device function or clinical outcomes at 5 years follow up, and an ongoing study will continue to monitor safety. ${ }^{72}$

Cho et $\mathrm{al}^{63}$ reported the results from a separate 60 -patient RCT, where 30 patients received discectomy and 30 received discectomy plus a boneanchored ACD. By 2 years, the ACD group had a significantly lower rate of $\mathrm{rLDH}(3.3 \%$ versus $20 \%$; $P=.04)$ compared to discectomy alone. Disc height was also better maintained at 2 years follow up in the bone-anchored ACD group compared to control $(86.3 \%$ versus $79.2 \% ; P=.04)$. Both groups experienced significant improvements in all patientreported outcomes related to leg and back pain, ODI, and quality of life $(P<.001)$. The authors reported that no complications, including device migration or loosening, were observed in any patients within the 2 years of follow up. ${ }^{63}$

In addition to the $2 \mathrm{RCTs}, 4$ prospective cohort studies and 1 retrospective analysis of a real-world treatment registry were identified (513 patients total). ${ }^{61,64,66-68}$ Each of these studies described positive treatment results with a bone-anchored $\mathrm{ACD}$, with $\mathrm{rLDH}$ rates ranging from $0 \%$ to $3.5 \%$ and reoperation rates ranging from 0 to $7.3 \%$ over a 1- to 5-year follow-up period. Device-related adverse events occurred at similar rates to the RCT $(2 \%-8.8 \%)$. The current evidence for bone-anchored annular closure is derived from 7 unique studies and 1123 patients (ACD: $\mathrm{n}=743$; control: $\mathrm{n}=380$ ). Collectively, this evidence indicates a positive benefit-risk ratio for lumbar discectomy patients with large annular defects, based on 
significant reductions in symptomatic rLDH and revision surgery in an at-risk population.

\section{Cost Effectiveness}

In addition to the clinical benefits, primary discectomy has been shown to be cost effective relative to nonsurgical care. A 1996 study found that discectomy increases quality-adjusted life years (QALYs) by 0.43 over 10 years at a nondiscounted cost of \$29200 per QALY ${ }^{73}$ More recent (2008 and 2011) studies from Tosteson et $\mathrm{al}^{74,75}$ reported that the costs for discectomy per QALY ranged from $\$ 34355$ to $\$ 69403$ over 2 years follow up and \$20 600 per QALY through 4 years. Furthermore, data from the National Health Interview Survey show that patients treated with discectomy return to work faster, miss fewer workdays, have increased average earnings, and the increased earnings offset the cost of surgery. ${ }^{76}$ When also considering the effects on employee productivity, surgical discectomy may yield a net societal cost savings. ${ }^{76}$

Compelling evidence has shown that primary discectomy is a safe and effective treatment for indicated patients, yet a minority of patients experience recurring symptoms, and some undergo revision surgery. Reoperation adds over $\$ 44000$ per patient in direct health care costs over 4 years following discectomy. ${ }^{77}$ With approximately 500000 discectomies per year in the United States, ${ }^{78}$ it is important from both economic and socioeconomic standpoints to identify evidence-based treatment strategies that help reduce the burden associated with revision surgeries after discectomy.

Among at-risk patients with large annular defects, we estimate there could be 24000 reoperations over any 2-year period in the United States, which are associated with a substantial economic and societal impact (Figure 1). Annular repair has reduced the rLDH-related reoperation rate by over $60 \%$ in a 2 -year time period, ${ }^{62}$ which should reduce the direct health care costs, allow more patients to return to work and stay at work, and avoid the significant morbidity associated with reoperation. Based on RCT data, a bone-anchored ACD was found to be cost effective at $\$ 6030$ per QALY over 2 years of follow up, which is well below the standard willingness-to-pay thresholds. ${ }^{79}$ When the societal costs of missed work and lower productivity were also considered, the incremental cost-effectiveness ratio of the bone-anchored ACD became negative, which indicates "economic dominance"-improved outcomes at a lower cost - compared to discectomy alone. $^{79}$

\section{COVERAGE RATIONALE}

Nonsurgical management is generally the first line of treatment for patients with LDH and radiculopathy. For patients with symptomatic LDH that fail to improve after 6 weeks of nonsurgical care or have severe symptoms that necessitate earlier intervention, large bodies of evidence indicate that discectomy is medically necessary and provides superior outcomes compared to continuing nonsurgical care. Each discectomy approach (open, microtubular, or endoscopic) has demonstrated similar clinical benefits and is appropriate for the surgical treatment of LDH with radiculopathy. The current high-level clinical evidence supports discectomy (open, microtubular, or endoscopic discectomy) as a medically necessary procedure for the treatment of LDH with radiculopathy in indicated patients.

In patients undergoing primary discectomy with a large ( $\geq 6 \mathrm{~mm}$ wide) annular defect, annular repair or closure is intended to control the risk of recurring symptoms and reoperation. Currently, the only annular repair technique supported by high-level clinical evidence is bone-anchored annular closure. A bone-anchored ACD is FDA-approved and indicated for patients with large annular defects. Adequate evidence is currently not available to support suturing of the annulus as an effective repair technique. The current clinical evidence supports bone-anchored annular closure for indicated patients to improve the probability of avoiding $\mathrm{rLDH}$ and sustaining the treatment benefits of discectomy.

\section{INDICATIONS/LIMITATIONS OF COVERAGE}

Patients who have the following clinical indications may be eligible for discectomy and coverage:

- Clinical signs and symptoms associated with $\mathrm{LDH}$,

- Imaging confirmation of LDH consistent with clinical findings,

- Failure to improve after 6 weeks of conservative care.

Clinical indications for annular closure and coverage include (based on the FDA-approved indications): 


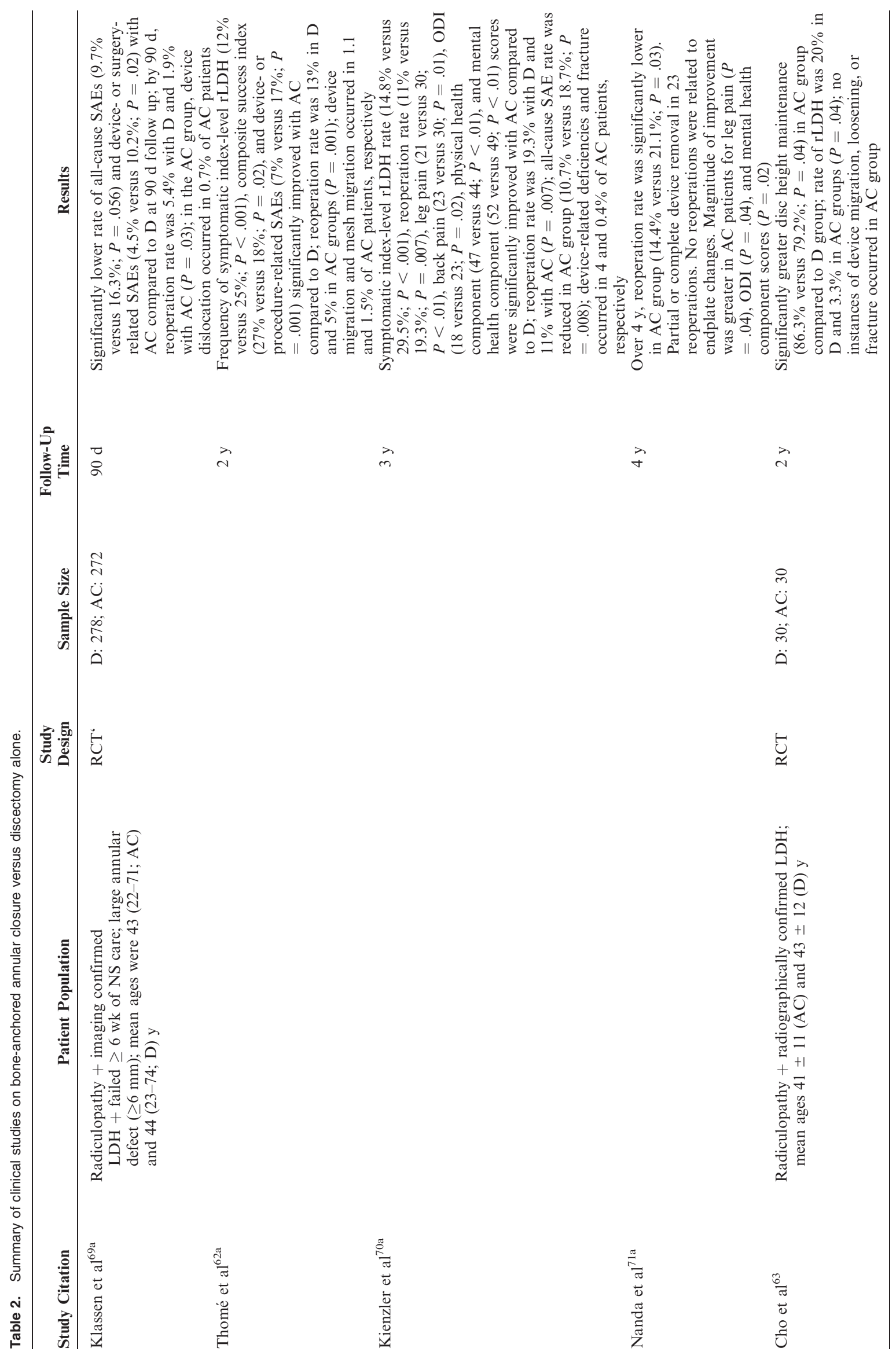




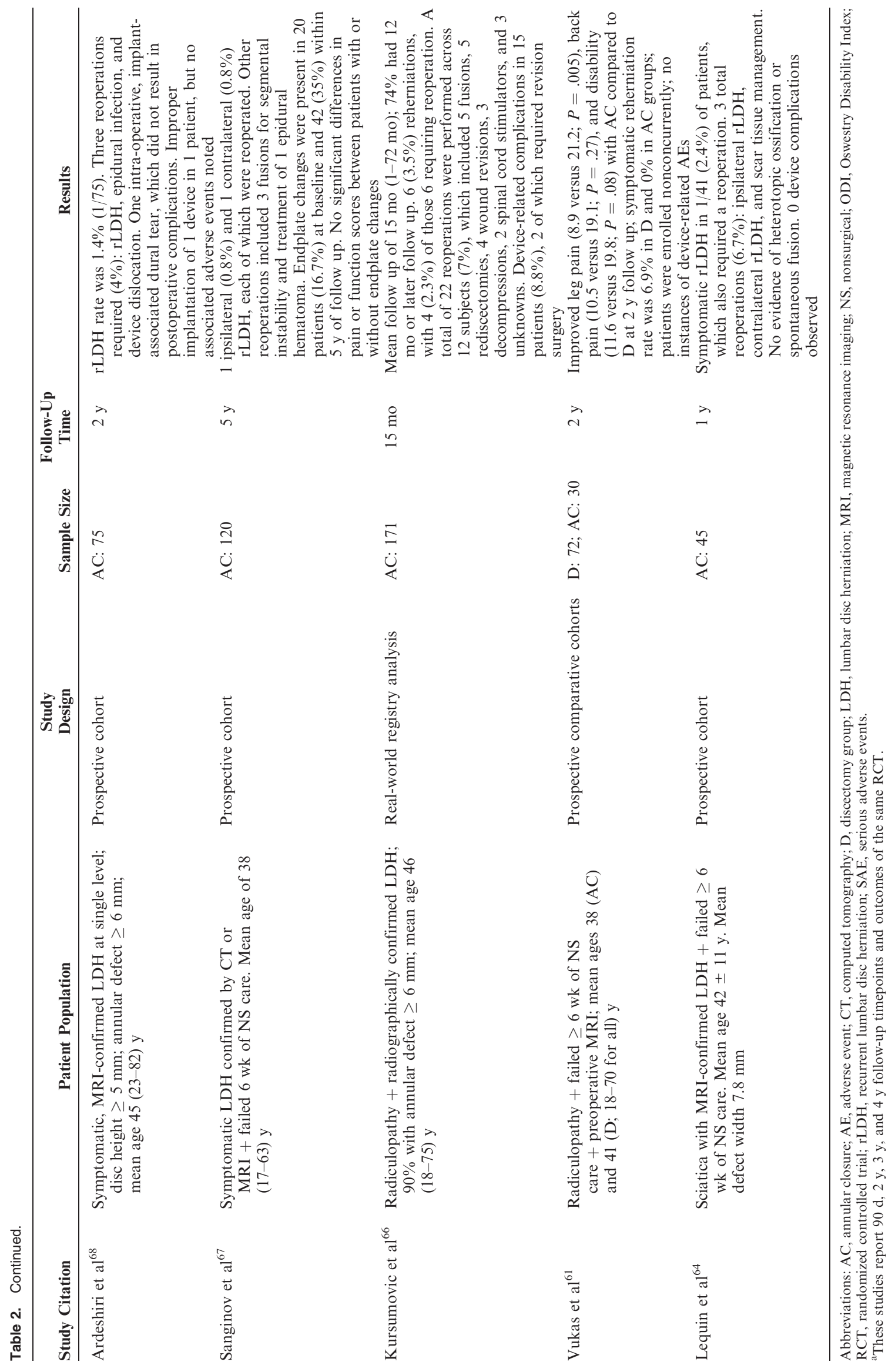




\section{Economic and Societal Impact of Reoperation Among Patients with Large Annular Defects}

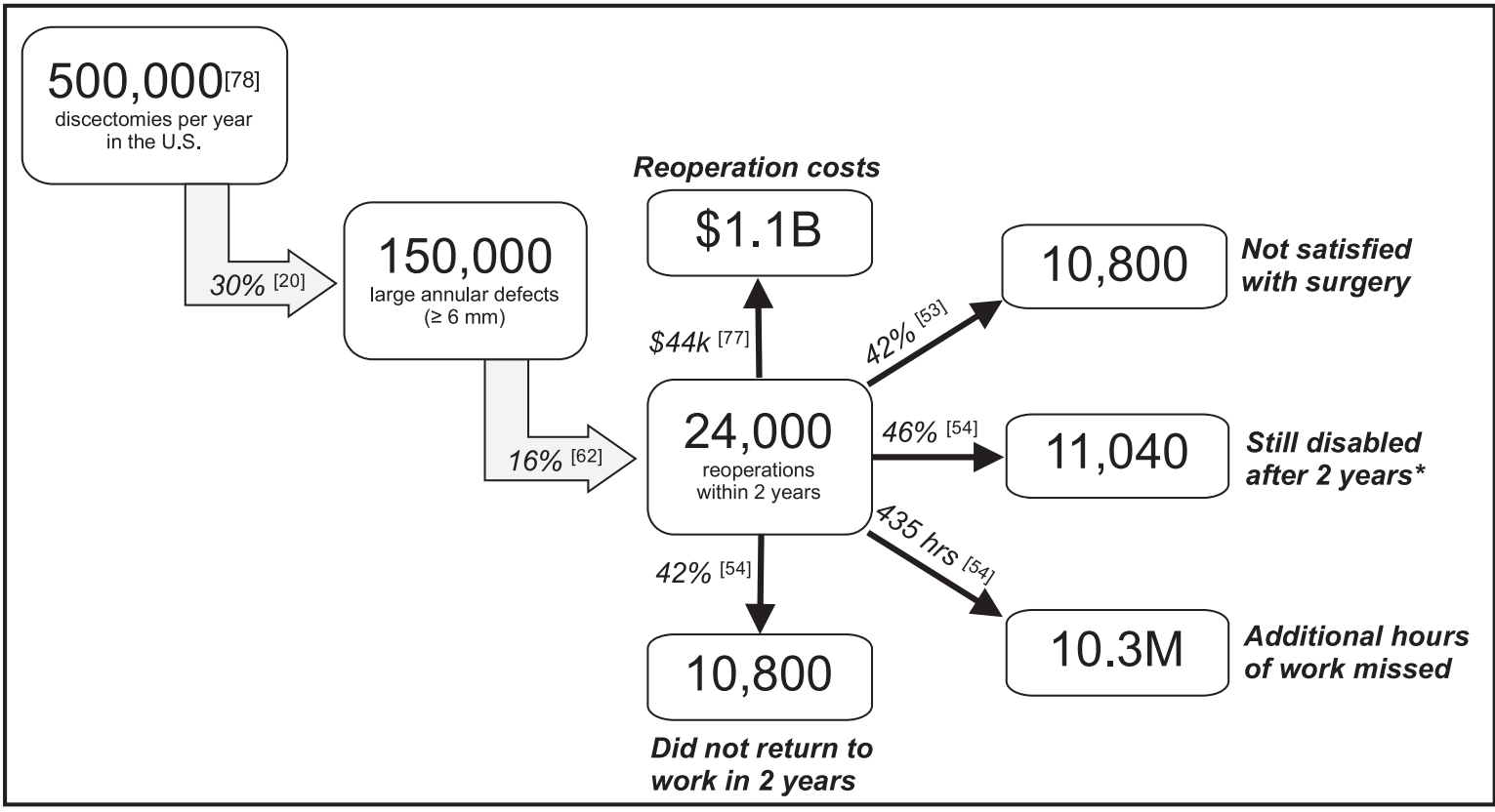

Figure 1. Estimated impact of rLDH-related reoperation among patients with large annular defects.

- Patient is indicated for a primary discectomy due to a posterior or posterolateral herniation,

- Discectomy will be performed at a single level that includes L4-L5 or L5-S1,

- The annular defect is large (between 4 and 6 $\mathrm{mm}$ tall and between 6 and $10 \mathrm{~mm}$ wide) after completion of the discectomy procedure.

\section{CODING}

\section{Procedural (Current Procedural Terminology} [CPT]) Coding

The American Medical Association recommends that posterior-posterolateral and/or revision lumbar discectomy be coded using CPT that are listed below. For purposes of CPT coding, the primary approach and visualization define the service. Unless otherwise specified, lumbar discectomy is presumed open (which includes microtubular approach).

\section{Definitions}

\section{Direct Visualization}

Light-based visualization can (only) be performed by eye or with surgical loupes, microscope, or endoscope.

\section{Open}

Spinal procedures with continuous direct (lightbased) visualization of the spine through a surgical opening.

\section{Endoscopic}

Spinal procedures performed with continuous direct (light-based) visualization of the spine through a surgical opening.

\section{CPT Codes}

63030

Laminotomy (hemilaminectomy) with decompression of nerve root(s), including partial facetectomy, foraminotomy, and/or excision of herniated intervertebral disc; 1 interspace, lumbar (for bilateral procedure, report 63030 with modifier 50).

\section{5}

Each additional interspace, lumbar (use 63035 in conjunction with 63030). (For bilateral procedure, report 63035 with modifier 50.)

\section{2}

Laminotomy (hemilaminectomy) with decompression of nerve root(s), including partial facectomy, foraminotomy, and/or excision of herniated inter- 
Table 3. Diagnosis codes (International Classification of Diseases, Tenth Revision, Clinical Modification [ICD10-CM]).

\begin{tabular}{ll}
\hline Diagnosis Code & \multicolumn{1}{c}{ Code Descriptor } \\
\hline M51 & $\begin{array}{c}\text { Thoracic, thoracolumbar, and lumbosacral } \\
\text { intervertebral disc disorders } \\
\text { With myelopathy }\end{array}$ \\
M51.0 & With radiculopathy \\
M51.1 & Other thoracic, thoracolumbar, and lumbosacral \\
M51.2 & intervertebral disc displacement \\
& Other thoracic, thoracolumbar, and lumbosacral \\
M51.3 & intervertebral disc degeneration \\
& Other thoracic, thoracolumbar, and lumbosacral \\
M51.8 & intervertebral disc disorders \\
Unspecified thoracic, thoracolumbar, and \\
lumbosacral intervertebral disc disorder \\
M48.00 & Spinal stenosis, site unspecified \\
M48.05 & Spinal stenosis, thoracolumbar region \\
M48.06 & Spinal stenosis, lumbar region \\
M48.07 & Spinal stenosis, lumbosacral region \\
M48.08 & Spinal stenosis, sacral and sacrococcygeal region \\
M47.1 & Other spondylosis with myelopathy \\
M47.2 & Other spondylosis with radiculopathy \\
M47.16 & Other spondylosis with myelopathy, lumbar region \\
M47.81 & Spondylosis without myelopathy or radiculopathy \\
M47.89 & Other spondylosis \\
M47.9 & Spondylosis, unspecified \\
M43.00 & Spondylolysis, site unspecified \\
M43.05 & Spondylolysis, thoracolumbar region \\
M43.06 & Spondylolysis, lumbar region \\
M43.08 & Spondylolysis, lumbosacral region \\
M53.09 & Spondylolysis, sacral and sacrococcygeal region \\
M54.8 & Spondylolysis, multiple sites in spine \\
Low back pain
\end{tabular}

vertebral, reexploration, single interspace, lumbar (for bilateral procedure, report 63042 with modifier $50)$.

\section{4}

Each additional lumbar interspace (list separately in addition to code for primary procedure; use 63044 in conjunction with 63042).

\section{6}

Transpedicular approach with decompression of spinal cord, equina, and/or nerve root(s) single segment; lumbar (including transfacet, or lateral extraforaminal approach; eg, far lateral herniated intervertebral disc).

\section{7}

Each additional segment, lumbar (list separately in addition to code for primary procedure; use 63057 in conjunction with 63056).

\section{0}

Endoscopic decompression of spinal cord, nerve root(s), including laminotomy, partial facectomy, foraminotomy, discectomy, and/or excision of herniated intervertebral disc, 1 interspace, lumbar (for bilateral procedure, report 62380 with modifier 50; effective date: January 2017).

\section{9}

Unlisted procedure, spine. Physicians may report CPT 22899 for implantation of the bone-anchored ACD in addition to the appropriate CPT code for the discectomy procedure (eg, 63030).

\section{Diagnostic (International Classification of Diseases, Tenth Revision, Clinical Modification [ICD10-CM]) Coding (diagnosis codes are listed in Table 3)}

\section{Hospital Outpatient-Ambulatory Surgical Center (ASC) Coding}

Medicare created a new Healthcare Common Procedure Coding System (HCPCS) code that specifically includes a bone-anchored ACD that hospital outpatient departments and ASCs should report for the procedure:

C9757. Laminotomy (hemilaminectomy), with decompression of nerve root(s), including partial facetectomy, foraminotomy and excision of herniated intervertebral disc, and repair of annular defect with implantation of bone anchored ACD, including annular defect measurement, alignment and sizing assessment, and image guidance; 1 interspace, lumbar (effective date: January 2020).

\section{DOCUMENTATION REQUIREMENTS}

(1) Radiculopathy confirmed on history and physical examination,

\section{$A N D$}

(2) EITHER

- Disabling leg or back pain refractory to 6 weeks of conservative care including any 1 of the following: time, physician structured exercise regimen, lumbar epidural therapy, or physical/chiropractic therapy,

$O R$

- Progressive neurologic deficit,

$A N D$

(3) Level appropriate documentation of nerve root compression on imaging (MRI or CT, prefer- 
ably with Myelogram) and/or nerve conduction velocity/electromyogram.

\section{CONCLUSIONS}

Discectomy is a safe and effective procedure for patients with primary LDH and radiculopathy who do not respond to nonsurgical care or have severe and deteriorating symptoms. The current evidence is consistently in favor of discectomy, rather than continuing nonsurgical care, for greater and/or faster alleviation of pain, reduction of disability, and higher patient satisfaction. Clinical evidence indicates that microtubular discectomy and endoscopic discectomy result in reduced incision size, soft tissue damage, and hospital stay and yield similar improvements in symptoms compared to open discectomy. Currently, evidence-based clinical recommendations for annular repair after discectomy do not exist. Patients who are indicated for discectomy and have a large annular defect are exposed to a greater risk of symptom recurrence and revision surgery and may benefit from annular repair. Current level 1 evidence demonstrates that, in appropriately selected patient populations, implantation of a bone-anchored ACD reduces the risk of symptom recurrence and revision surgery compared to discectomy alone. The current evidence supports the use of discectomy as well as consideration for bone-anchored annular repair for the treatment of indicated patients with primary symptomatic LDH who may otherwise be at higher risk for recurrent disc herniation. (This ISASS Policy addresses only LDH with radiculopathy that is clinically appropriate for direct visualization [open, microtubular, or endoscopic discectomy]; the particular primary posterior/posterolateral surgical procedural approach is the purview of the surgeon.)

\section{REFERENCES}

1. Kreiner DS, Hwang SW, Easa JE, et al. An evidencebased clinical guideline for the diagnosis and treatment of lumbar disc herniation with radiculopathy. Spine $J$. 2014;14(1):180-191.

2. Fardon DF, Milette PC; Combined Task Forces of the North American Spine Society, American Society of Spine Radiology, American Society of Neuroradiology. Nomenclature and classification of lumbar disc pathology. Recommendations of the combined task forces of the North American Spine Society, American Society of Spine Radiology, and American Society of Neuroradiology. Spine (Phila Pa 1976). 2001;26(5):E93-E113.
3. Frymoyer JW. Back pain and sciatica. $N$ Engl J Med. 1988;318(5):291-300.

4. Amin RM, Andrade NS, Neuman BJ. Lumbar disc herniation. Curr Rev Musculoskelet Med. 2017;10(4):507-516.

5. Koes BW, van Tulder MW, Peul WC. Diagnosis and treatment of sciatica. BMJ. 2007;334(7607):1313-1317.

6. Tawa N, Rhoda A, Diener I. Accuracy of clinical neurological examination in diagnosing lumbo-sacral radiculopathy: a systematic literature review. BMC Musculoskelet Disord. 2017;18(1):93.

7. Janssen ME, Bertrand SL, Joe C, Levine MI. Lumbar herniated disk disease: comparison of MRI, myelography, and post-myelographic CT scan with surgical findings. Orthopedics. 1994;17(2):121-127.

8. Mysliwiec LW, Cholewicki J, Winkelpleck MD, Eis GP. MSU classification for herniated lumbar discs on MRI: toward developing objective criteria for surgical selection. Eur Spine J. 2010;19(7):1087-1093.

9. Wong JJ, Cote P, Sutton DA, et al. Clinical practice guidelines for the noninvasive management of low back pain: a systematic review by the Ontario Protocol for Traffic Injury Management (OPTIMa) Collaboration. Eur J Pain. 2017;21(2):201-216.

10. Dagenais S, Tricco AC, Haldeman S. Synthesis of recommendations for the assessment and management of low back pain from recent clinical practice guidelines. Spine $J$. 2010;10(6):514-529.

11. Peul WC, van Houwelingen HC, van den Hout WB, et al. Surgery versus prolonged conservative treatment for sciatica. $N$ Engl J Med. 2007;356(22):2245-2256.

12. Osterman H, Seitsalo S, Karppinen J, Malmivaara A. Effectiveness of microdiscectomy for lumbar disc herniation: a randomized controlled trial with 2 years of follow-up. Spine (Phila Pa 1976). 2006;31(21):2409-2414.

13. Buttermann GR. Treatment of lumbar disc herniation: epidural steroid injection compared with discectomy. A prospective, randomized study. J Bone Joint Surg Am. 2004;86(4):670-679.

14. Weinstein JN, Tosteson TD, Lurie JD, et al. Surgical vs nonoperative treatment for lumbar disk herniation: the Spine Patient Outcomes Research Trial (SPORT): a randomized trial. JAMA. 2006;296(20):2441-2450.

15. Gadjradj PS, Arts MP, van Tulder MW, Rietdijk WJR, Peul WC, Harhangi BS. Management of symptomatic lumbar disk herniation: an international perspective. Spine (Phila $\mathrm{Pa}$ 1976). 2017;42(23):1826-1834.

16. Health Technology Clinical Committee Findings and Decision. Paper presented at: Surgery for lumbar radiculopathy/sciatica; May 18, 2018; SeaTac Conference Center, Seattle, Washington.

17. Washington State Healthcare Authority. Health Technology Assessment Program. Surgery for Lumbar Radiculopathy/Sciatica: Final evidence report. April 13, 2018. https:// www.hca.wa.gov/assets/program/lumbar-radiculopathy-finalrpt-2180418.pdf. Accessed July 1, 2019.

18. Fjeld OR, Grovle L, Helgeland J, et al. Complications, reoperations, readmissions, and length of hospital stay in 34639 surgical cases of lumbar disc herniation. Bone Joint J. 2019;101$\mathrm{B}(4): 470-477$.

19. Carragee EJ, Han MY, Suen PW, Kim D. Clinical outcomes after lumbar discectomy for sciatica: the effects of 
fragment type and anular competence. J Bone Joint Surg Am. 2003;85(1):102-108.

20. Miller LE, McGirt MJ, Garfin SR, Bono CM. Association of annular defect width after lumbar discectomy with risk of symptom recurrence and reoperation: systematic review and meta-analysis of comparative studies. Spine (Phila Pa 1976). 2018;43(5):E308-E315.

21. Atlas SJ, Deyo RA, Keller RB, et al. The Maine Lumbar Spine Study, Part II. 1-year outcomes of surgical and nonsurgical management of sciatica. Spine (Phila Pa 1976). 1996;21(15):1777-1786.

22. Gugliotta M, da Costa BR, Dabis E, et al. Surgical versus conservative treatment for lumbar disc herniation: a prospective cohort study. BMJ Open. 2016;6(12):e012938.

23. Weinstein JN, Lurie JD, Tosteson TD, et al. Surgical vs nonoperative treatment for lumbar disk herniation: the Spine Patient Outcomes Research Trial (SPORT) observational cohort. JAMA. 2006;296(20):2451-2459.

24. McMorland G, Suter E, Casha S, du Plessis SJ, Hurlbert RJ. Manipulation or microdiskectomy for sciatica? A prospective randomized clinical study. J Manipulative Physiol Ther. 2010;33(8):576-584.

25. Thomas KC, Fisher CG, Boyd M, Bishop P, Wing P, Dvorak MF. Outcome evaluation of surgical and nonsurgical management of lumbar disc protrusion causing radiculopathy. Spine (Phila Pa 1976). 2007;32(13):1414-1422.

26. Atlas SJ, Keller RB, Chang Y, Deyo RA, Singer DE. Surgical and nonsurgical management of sciatica secondary to a lumbar disc herniation: five-year outcomes from the Maine Lumbar Spine Study. Spine (Phila Pa 1976). 2001;26(10):11791187.

27. Atlas SJ, Keller RB, Wu YA, Deyo RA, Singer DE. Long-term outcomes of surgical and nonsurgical management of lumbar spinal stenosis: 8 to 10 year results from the maine lumbar spine study. Spine (Phila Pa 1976). 2005;30(8):936-943.

28. McCoy CE. Understanding the intention-to-treat principle in randomized controlled trials. West J Emerg Med. 2017;18(6):1075-1078.

29. Hernan MA, Hernandez-Diaz S. Beyond the intentionto-treat in comparative effectiveness research. Clin Trials. 2012;9(1):48-55.

30. Pearson A, Lurie J, Tosteson T, et al. Who should have surgery for an intervertebral disc herniation? Comparative effectiveness evidence from the spine patient outcomes research trial. Spine (Phila Pa 1976). 2012;37(2):140-149.

31. Weinstein JN, Lurie JD, Tosteson TD, et al. Surgical versus nonoperative treatment for lumbar disc herniation: fouryear results for the Spine Patient Outcomes Research Trial (SPORT). Spine (Phila Pa 1976). 2008;33(25):2789-2800.

32. Lurie JD, Tosteson TD, Tosteson AN, et al. Surgical versus nonoperative treatment for lumbar disc herniation: eight-year results for the spine patient outcomes research trial. Spine (Phila Pa 1976). 2014;39(1):3-16.

33. Kerr D, Zhao W, Lurie JD. What are long-term predictors of outcomes for lumbar disc herniation? A randomized and observational study. Clin Orthop Relat Res. 2015;473(6):1920-1930.

34. Arts MP, Kursumovic A, Miller LE, et al. Comparison of treatments for lumbar disc herniation: systematic review with network meta-analysis. Medicine (Baltimore). 2019;98(7):e14410.
35. Lurie JD, Henderson ER, McDonough CM, et al. Effect of expectations on treatment outcome for lumbar intervertebral disc herniation. Spine (Phila Pa 1976). 2016;41(9):803-809.

36. Gibson JN, Waddell G. Surgical interventions for lumbar disc prolapse: updated Cochrane Review. Spine (Phila Pa 1976). 2007;32(16):1735-1747.

37. Ahn Y. Endoscopic spine discectomy: indications and outcomes. Int Orthop. 2019;43(4):909-916.

38. Ruetten S, Komp M, Merk H, Godolias G. Fullendoscopic interlaminar and transforaminal lumbar discectomy versus conventional microsurgical technique: a prospective, randomized, controlled study. Spine (Phila Pa 1976). 2008;33(9):931-939.

39. Rasouli MR, Rahimi-Movaghar V, Shokraneh F, Moradi-Lakeh M, Chou R. Minimally invasive discectomy versus microdiscectomy/open discectomy for symptomatic lumbar disc herniation. Cochrane Database Syst Rev. 2014(9):CD010328.

40. Butler AJ, Alam M, Wiley K, Ghasem A, Rush IA, Wang JC. Endoscopic lumbar surgery: the state of the art in 2019. Neurospine. 2019;16(1):15-23.

41. Hermantin FU, Peters T, Quartararo L, Kambin P. A prospective, randomized study comparing the results of open discectomy with those of video-assisted arthroscopic microdiscectomy. J Bone Joint Surg Am. 1999;81(7):958-965.

42. Gibson JNA, Subramanian AS, Scott CEH. A randomised controlled trial of transforaminal endoscopic discectomy vs microdiscectomy. Eur Spine J. 2017;26(3):847-856.

43. Lee SH, Chung SE, Ahn Y, Kim TH, Park JY, Shin SW. Comparative radiologic evaluation of percutaneous endoscopic lumbar discectomy and open microdiscectomy: a matched cohort analysis. Mt Sinai J Med. 2006;73(5):795-801.

44. Ahn SS, Kim SH, Kim DW, Lee BH. Comparison of outcomes of percutaneous endoscopic lumbar discectomy and open lumbar microdiscectomy for young adults: a retrospective matched cohort study. World Neurosurg. 2016;86:250-258.

45. Zhang B, Liu S, Liu J, et al. Transforaminal endoscopic discectomy versus conventional microdiscectomy for lumbar discherniation: a systematic review and meta-analysis. J Orthop Surg Res. 2018;13(1):169.

46. Huang W, Han Z, Liu J, Yu L, Yu X. Risk factors for recurrent lumbar disc herniation: a systematic review and metaanalysis. Medicine (Baltimore). 2016;95(2):e2378.

47. Tanavalee $\mathrm{C}$, Limthongkul W, Yingsakmongkol W, Luksanapruksa P, Singhatanadgige W. A comparison between repeat discectomy versus fusion for the treatment of recurrent lumbar disc herniation: systematic review and meta-analysis. $J$ Clin Neurosci. 2019;66:202-208.

48. Parker SL, Mendenhall SK, Godil SS, et al. Incidence of low back pain after lumbar discectomy for herniated disc and its effect on patient-reported outcomes. Clin Orthop Relat Res. 2015;473(6):1988-1999.

49. Virk SS, Diwan A, Phillips FM, Sandhu H, Khan SN. What is the rate of revision discectomies after primary discectomy on a national scale? Clin Orthop Relat Res. 2017;475(11):2752-2762.

50. Elkan P, Lagerback T, Moller H, Gerdhem P. Response rate does not affect patient-reported outcome after lumbar discectomy. Eur Spine J. 2018;27(7):1538-1546.

51. Vik A, Zwart JA, Hulleberg G, Nygaard OP. Eight year outcome after surgery for lumbar disc herniation: a comparison 
of reoperated and not reoperated patients. Acta Neurochir (Wien). 2001;143(6):607-610; discussion 610-611.

52. Abdu RW, Abdu WA, Pearson AM, Zhao W, Lurie JD, Weinstein JN. Reoperation for recurrent intervertebral disc herniation in the Spine Patient Outcomes Research Trial: analysis of rate, risk factors, and outcome. Spine (Phila Pa 1976). 2017;42(14):1106-1114.

53. Fritzell P, Knutsson B, Sanden B, Stromqvist B, Hagg O. Recurrent versus primary lumbar disc herniation surgery: patient-reported outcomes in the Swedish Spine Register Swespine. Clin Orthop Relat Res. 2015;473(6):1978-1984.

54. Klassen PD, Hsu WK, Martens F, et al. Post-lumbar discectomy reoperations that are associated with poor clinical and socioeconomic outcomes can be reduced through use of a novel annular closure device: results from a 2-year randomized controlled trial. Clinicoecon Outcomes Res. 2018;10:349-357.

55. Lebow RL, Adogwa O, Parker SL, Sharma A, Cheng J, McGirt MJ. Asymptomatic same-site recurrent disc herniation after lumbar discectomy: results of a prospective longitudinal study with 2-year serial imaging. Spine (Phila Pa 1976). 2011;36(25):2147-2151.

56. Leven D, Passias PG, Errico TJ, et al. Risk factors for reoperation in patients treated surgically for intervertebral disc herniation: a subanalysis of eight-year SPORT data. J Bone Joint Surg Am. 2015;97(16):1316-1325.

57. Nolte M, Basques BA, Louie PK, et al. Patients undergoing revision microdiskectomy for recurrent lumbar disk herniation experience worse clinical outcomes and more revision surgeries compared with patients undergoing a primary microdiskectomy. J Am Acad Orthop Surg. 2019;27(17):e796e803.

58. Osterman H, Sund R, Seitsalo S, Keskimaki I. Risk of multiple reoperations after lumbar discectomy: a populationbased study. Spine (Phila Pa 1976). 2003;28(6):621-627.

59. Ammerman J, Watters WC, Inzana JA, Carragee G, Groff MW. Closing the treatment gap for lumbar disc herniation patients with large annular defects: a systematic review of techniques and outcomes in this high-risk population. Cureus. 2019;11(5):e4613.

60. Bailey A, Araghi A, Blumenthal S, Huffmon GV; Anular Repair Clinical Study Group. Prospective, multicenter, randomized, controlled study of anular repair in lumbar discectomy: two-year follow-up. Spine (Phila Pa 1976). 2013;38(14):1161-1169.

61. Vukas D, Ledic D, Grahovac G, Kolic Z, Rotim K, Vilendecic M. Clinical outcomes in patients after lumbar disk surgery with annular reinforcement device: two-year follow up. Acta Clin Croat. 2013;52(1):87-91.

62. Thome C, Klassen PD, Bouma GJ, et al. Annular closure in lumbar microdiscectomy for prevention of reherniation: a randomized clinical trial. Spine J. 2018;18(12):2278-2287.

63. Cho PG, Shin DA, Park SH, Ji GY. Efficacy of a novel annular closure device after lumbar discectomy in Korean patients: a 24-month follow-up of a randomized controlled trial. J Korean Neurosurg Soc. 2019;62(6):691-699.

64. Lequin MB, Barth M, Thome C, Bouma GJ. Primary limited lumbar discectomy with an annulus closure device: oneyear clinical and radiographic results from a prospective, multicenter study. Korean J Spine. 2012;9(4):340-347.

65. Kursumovic A, Rath SA. Effectiveness of an annular closure device in a "real-world" population: stratification of registry data using screening criteria from a randomized controlled trial. Med Devices (Auckl). 2018;11:193-200.

66. Kursumovic A, Rath S. Performance of an annular closure device in a 'real-world', heterogeneous, at-risk, lumbar discectomy population. Cureus. 2017;9(11):e1824.

67. Sanginov AJ, Krutko AV, Baykov ES, Lutsik AA. Outcomes of surgical treatment of lumbar disc herniation using an annular closure device. Coluna/Columna. 2018;17(3):188194.

68. Ardeshiri A, Miller LE, Thome C. Two-year real-world results of lumbar discectomy with bone-anchored annular closure in patients at high risk of reherniation. Eur Spine J. 2019.

69. Klassen PD, Bernstein DT, Kohler HP, et al. Boneanchored annular closure following lumbar discectomy reduces risk of complications and reoperations within 90 days of discharge. J Pain Res. 2017;10:2047-2055.

70. Kienzler JC, Klassen PD, Miller LE, et al. Three-year results from a randomized trial of lumbar discectomy with annulus fibrosus occlusion in patients at high risk for reherniation. Acta Neurochir (Wien). 2019.

71. Nanda D, Arts MP, Miller LE, et al. Annular closure device lowers reoperation risk 4 years after lumbar discectomy. Med Devices (Auckl). 2019;12:327-335.

72. U.S. Food and Drug Administration. FDA Summary of Safety and Effectiveness Data (SSED). Barricaid ${ }^{\circledR}$ Anular Closure Device (ACD). PMA P160050. https://www.accessda ta.fda.gov/cdrh_docs/pdf16/P160050B.pdf. Accessed July 16, 2019.

73. Malter AD, Larson EB, Urban N, Deyo RA. Costeffectiveness of lumbar discectomy for the treatment of herniated intervertebral disc. Spine (Phila Pa 1976). 1996;21(9):1048-1054; discussion 1055.

74. Tosteson AN, Skinner JS, Tosteson TD, et al. The cost effectiveness of surgical versus nonoperative treatment for lumbar disc herniation over two years: evidence from the Spine Patient Outcomes Research Trial (SPORT). Spine (Phila Pa 1976). 2008;33(19):2108-2115.

75. Tosteson AN, Tosteson TD, Lurie JD, et al. Comparative effectiveness evidence from the spine patient outcomes research trial: surgical versus nonoperative care for spinal stenosis, degenerative spondylolisthesis, and intervertebral disc herniation. Spine (Phila Pa 1976). 2011;36(24):2061-2068.

76. Koenig L, Dall TM, Gu Q, Saavoss J, Schafer MF. How does accounting for worker productivity affect the measured cost-effectiveness of lumbar discectomy? Clin Orthop Relat Res. 2014;472(4):1069-1079.

77. Heindel P, Tuchman A, Hsieh PC, et al. Reoperation rates after single-level lumbar discectomy. Spine (Phila $\mathrm{Pa}$ 1976). 2017;42(8):E496-E501.

78. Gray DT, Deyo RA, Kreuter W, et al. Population-based trends in volumes and rates of ambulatory lumbar spine surgery. Spine (Phila Pa 1976). 2006;31(17):1957-1963; discussion 1964.

79. Ament J, Thaci B, Yang Z, et al. Cost-effectiveness of a bone-anchored annular closure device versus conventional lumbar discectomy in treating lumbar disc herniations. Spine (Phila Pa 1976). 2019;44(1):5-16.

Disclosures and COI: JI: salaried employee of Telos Partners, LLC, which received payments from 
ISASS to support literature review and manuscript development. Telos Partners, LLC, has received fees unrelated to this manuscript from entities in the spine space, including Zimmer Biomet, Orthopediatrics, Intrinsic Therapeutics, K2M, Medacta International, Merit Medical, Wenzel Spine, and SiNtx Technologies. CWK: Consultant for Elliquence, paid member of Mock FDA Advisory Panel for Intrinsic Therapeutics. AA: Consulting fees from Intrinsic Therapeutics. JY: Consultant for Elliquence Spine, Vertical Spine, Aesculap Spine. ML: None.
Corresponding Author: Morgan Lorio, MD, FACS, Advanced Orthopedics, 499 E. Central Parkway, Altamonte Springs, FL 32701. Phone: (407) 960-1717; Email: mloriomd@gmail.com.

Published 29 February 2020

This manuscript is generously published free of charge by ISASS, the International Society for the Advancement of Spine Surgery. Copyright (C) 2020 ISASS. To see more or order reprints or permissions, see http://ijssurgery.com. 